\title{
Neuer Hausarzt-EBM kommt nun doch
}

— In einer (geheimen) Sitzung hat die KBV-Vertreterversammlung am 26. Mai 2013 in Hannover Eckpunkte zu einer zweistufigen Einführung des neuen HausarztEBM beschlossen. In einer ersten Stufe sollen zum 1.10.2013 die versorgungsbereichsspezifische Grundpauschale und ein ausführliches Einzelgespräch aus der Versichertenpauschale herausgelöst werden. Das Einzelgespräch soll nicht nur einmal im Behandlungsfall berechnungsfähig sein, sondern einem Praxisbudget unterworfen werden. Eine Zeitvorgabe soll nicht erfolgen oder sehr gering ausfallen.

Die sog. Chronikerpauschale soll künftig ausschließlich nach medizinischen Gesichtspunkten ansatzfähig sein, d.h. der Arzt soll mit dem Ansatz selbst bestimmen können, ob eine (nach seiner Auffassung) chronische Erkrankung vorliegt oder nicht. Die Ziffer soll allerdings in Abhängigkeit davon vergütet werden, ob es nur zu einem oder mehreren Quartalskontakten mit dem Patienten kommt. Die ursprüng- lich geplante ICD 10-Koppelung bei der Vergütung der Leistung ist damit vom Tisch. Strittig ist noch, ob das EKG und der Taschendoppler gesondert berechnungsfähig werden. Das wollen die Kassen angeblich nicht. Die Basisziffern für Geriatrie und Palliativmedizin hingegen sollen auch zum 1.10.2013 eingeführt werden und zwar ohne jegliche zusätzliche Qualifikationsanforderungen. Ab dem 1.7.2014 sollen dann die speziellen Leistungen aus diesem Bereich, finanziert mit "frischem" Geld der
Kassen, folgen. Ebenfalls ab 1.7.2014 will man dann das höchst umstrittene Budgetierungssystem auf der Basis der Leistungskalkulation („AL-/TL-System“) einführen. Hier haben die Kassen angeblich schon zugestimmt. Vor einer endgültigen Entscheidung will die KBV aber noch Probeberechnungen vorlegen und in einer Sonder-Vertreterversammlung spätestens zum 30.6.2013 präsentieren

\section{MMW Kommentar}

Damit sieht es so aus, als ob die vielfältigen Widerstände gegen diese bisher völlig unsinnige EBM-Reform erfolglos verlaufen würden. Angesichts der ebenfalls ab dem 1. Oktober 2013 geplanten Neugestaltung der Trennung der Gesamtvergütung in einen hausärztlichen und einen fachärztlichen Anteil gewinnt der Ansatz aber doch noch an Bedeutung. Der Trennungsbetrag und damit der hausärztliche Anteil soll nämlich aus den tatsächlichen Abrechnungen der noch folgenden Quartale 4/2013 bis 3/2014 resultieren. Wichtig wird deshalb sein, dass dieser neue EBM - wenn er tatsächlich kommt - von Anfang an und damit ab dem 1. Oktober 2013 konsequent umgesetzt wird. Beachten Sie deshalb unsere zurückliegende Dokumentation zur EBM-Reform (MMW Nr. 6-9/2013), die weitestgehend den nunmehr beschlossenen Eckpunkten entspricht.

\section{Verstoß gegen Konkurrenzschutz berechtigt zur Mietminderung}

\begin{abstract}
- Einem Urteil des Bundesgerichtshofs (BGH) zufolge stellt die Verletzung der in einem Gewerberaummietvertrag vereinbarten Konkurrenzschutzklausel durch den Vermieter einen Mangel der Mietsache dar (Az.: XII ZR 177/10 vom 10. Oktober 2012). Im zugrunde liegenden Fall klagte ein Facharzt für Orthopädie, weil der Besitzer des Hauses, in dem sich seine Mieträume befinden, nur wenige Jahre später auch Räume an einen Facharzt für Chirurgie im selben Haus vermietete. Dabei machte er eine Mietminderung um $50 \%$ geltend. Dies bestätigte der BGH in
\end{abstract}

seinem Urteil, weil nach Auffassung der Richter der im Mietvertrag gewährte Konkurrenzschutz die Leistungen der anderen Praxis umfasst. Darüber hinaus kam der $\mathrm{BGH}$ in seinen Entscheidungsgründen

\section{MMW Kommentar}

Dieses Urteil des BGH ist so gesehen von grundsätzlicher Bedeutung, denn nach Auffassung der Richter besteht $z$. B. für eine Arztpraxis sogar ohne eine entsprechende vertragliche Vereinbarung im Mietvertrag ein solcher Konkurrenzschutz. Bei einem Verstoß gegen diesen Grundsatz kann eine aber noch zu dem Ergebnis, dass ein Verstoß gegen den Konkurrenzschutz grundsätzlich einen Mangel der Mietsache darstellt, der zur Minderung der Miete berechtigt.

Mietminderung beansprucht werden. $\mathrm{Ob}$ und gegebenenfalls in welcher Höhe eine solche Minderung dann allerdings erfolgen kann, ist eine Frage des Einzelfalles. Maßgeblich ist alleine der Schaden, d.h. in welchem Ausmaß der Betrieb der Praxis durch die Konkurrenz beeinträchtigt wird. 